\title{
Kaustia mangrovi gen. nov., sp. nov. isolated from Red Sea mangrove sediments belongs to the recently proposed Parvibaculaceae family within the order Rhizobiales
}

\author{
Fatmah O. Sefrji, Ramona Marasco, Grégoire Michoud, Kholoud A. Seferji, Giuseppe Merlino and Daniele Daffonchio*
}

\begin{abstract}
We isolated a novel strain, R1DC25 ${ }^{\top}$, described as Kaustia mangrovi gen. nov. sp. nov. from the sediments of a mangrove forest on the coast of the Red Sea in Saudi Arabia. This isolate is a moderately halophilic, aerobic/facultatively anaerobic Gram-stainnegative bacterium showing optimum growth at between 30 and $40^{\circ} \mathrm{C}$, at a pH of 8.5 and with $3-5 \% \mathrm{NaCl}$. The genome of R1DC25 $5^{\top}$ comprises a circular chromosome that is 4630536 bp in length, with a DNA G+C content of 67.3 mol\%. Phylogenetic analyses based on the $16 \mathrm{~S}$ rRNA gene sequence and whole-genome multilocus sequence analysis of 120 concatenated singlecopy genes revealed that R1DC25 represents a distinct lineage within the family Parvibaculaceae in the order Rhizobiales within the class Alphaproteobacteria. R1DC25 showing 95.8, 95.3 and 94.5\% 16S rRNA gene sequence identity with Rhodoligotrophos appendicifer, Rhodoligotrophos jinshengii and Rhodoligotrophos defluvii, respectively. The predominant quinone was Q-10, and the polar lipids were phosphatidylglycerol, phosphatidylcholine, diphosphatidylglycerol, as well as several distinct aminolipids and lipids. The predominant cellular fatty acids were $\mathrm{C}_{19: 0}$ cyclo $\omega 8 \mathrm{c}$, a combination of $\mathrm{C}_{18: 1} \omega 7 \mathrm{c}$ and/or $\mathrm{C}_{18: 1} \omega 6 \mathrm{c}$ and $\mathrm{C}_{16: 0}$. On the basis of the differences in the phenotypic, physiological and biochemical characteristics from its known relatives and the results of our phylogenetic analyses, $\mathrm{R}^{\mathrm{DDC}} 25^{\top}\left(=\mathrm{KCTC} 72348^{\mathrm{T}} ;=\mathrm{JCM} 33619^{\top} ;=\mathrm{NCCB} 100699^{\top}\right)$ is proposed to represent a novel species in a novel genus, and we propose the name Kaustia mangrovi gen. nov., sp. nov. (Kaustia, subjective name derived from the abbreviation KAUST for King Abdullah University of Science and Technology; mangrovi, of a mangrove).
\end{abstract}

\section{INTRODUCTION}

Recent developments in technology have led to significant increases in our understanding of the extent of microbial diversity. Many species have been described using omics-based approaches, but a huge knowledge gap still exists between the genomic potential assessment and function assignment to genes and proteins [1]. By cultivating species, researchers can expand the available data about microbes and their genomes, even for those species that are not easily detected by molecular methods due to their scarcity in the environment, i.e. they are members of the rare biosphere [2]. The isolation and characterization of novel microbes from conventional and overlooked ecosystems remain a cornerstone of research in microbiology [3]. 'Hidden' microbial strains can sometimes be detected using alternative cultivation strategies, such as diffusion chambers (DCs) $[4,5]$. In the present study, we used this novel approach to investigate the microbial diversity of the subtropical mangrove sediments in the arid environment of the coast of the Red Sea, an unexplored natural ecosystem. Mangrove forests are highly productive ecosystems and are widespread in tropical and subtropical coastlines, with a coverage of $60-70 \%$ [6-9]. Mangroves represent unique ecological niches as they host a diverse variety of microorganisms [10-12]. It has been estimated that the bacteria in

Author affiliations: ${ }^{1}$ Biological and Environmental Sciences and Engineering Division (BESE), Red Sea Research Center (RSRC), King Abdullah University of Science and Technology (KAUST), Thuwal, Saudi Arabia.

*Correspondence: Daniele Daffonchio, daniele.daffonchio@kaust.edu.sa

Keywords: Kaustia; mangrove; Red Sea sediment; osmoadaptation; Rhizobiales; cultivation; diffusion chamber.

Abbreviations: ANI, average nucleotide identity; DC, diffusion chamber; dDDH, DNA-DNA hybridization; PGP, plant growth promoting; POCP, percentage of conserved proteins.

The GenBank accession number for the 16S rRNA gene sequence of strain R1DC9' extracted from the genome DNA sequence is MT146883. The whole-genome shotgun sequence project was deposited at DDBJ/EMBL/GenBank under the following accession identification: CP028923.1. The 165 rRNA gene sequences of the bacterial isolates from mangrove sediments were submitted to NCBI under the accession numbers MW644816MW644868. GenBank accession numbers for the 16S rRNA gene sequence and whole-genome sequence of R1DC25 are MT146881 and CP058214, respectively.

Four supplementary figures and six supplementary tables are available with the online version of this article. 004806 (c) 2021 The Authors 
mangrove sediments constitute up to $80 \%$ of the total living biomass of these ecosystems [13-16] and play a key role in their functioning [12]. However, relatively few studies have focused on the exploration and characterization of the microbial diversity of mangrove sediments [7, 10, 11, 13, 14, 17-27] and the cultivable fraction of microbes therein [28-34]. The cultivable bacterial strains obtained from mangrove sediments include members of well-characterized genera, such as Bacillus, Halobacillus, Microbacterium, Novosphingobium, Paracoccus, Streptomyces, Thalassotalea and Vibrio [30, 33, 35-39], and several novel genera, including Acidimangrovimonas, Mangroviflexus, Mangrovibacterium, Marisediminitalea, Mangrovicoccus, Mangrovitalea, Mangrovimonas and Zhengella [32, 34, 40-45]; these data clearly confirm the untapped diversity harboured by mangrove sediments. In this research, we used an inoculum of sediments collected from the mangrove forest of Avicennia marina in the Ibn-Sina Research Station, King Abdullah University of Science and Technology (KAUST), Saudi Arabia, located on the coast of the Red Sea. We isolated and described a novel culturable bacteria, Kaustia mangrovi gen. nov. sp. nov., belonging to the order Rhizobiales, class Alphaproteobacteria, family Parvibaculaceae. The order Rhizobiales, the taxonomy of which was recently modified [46], includes bacterial species that are ecologically important for soil, animals and plants [10, 47] and may also be important in the mangrove ecosystem. In this paper, we describe the genomic, physicochemical and metabolic features of R1DC25 .

\section{ISOLATION AND HABITAT}

R1DC25 $5^{\mathrm{T}}$ was isolated under aerobic conditions from Red Sea mangrove sediments using DC-based in-situ cultivation [5]. Mangrove sediments were collected in 2017 from the Ibn-Sina Research Station $\left(22.34^{\circ} \mathrm{N}, 39.09^{\circ} \mathrm{E}\right)$ within the KAUST campus on the coast of the Red Sea of Saudi Arabia. The physiochemical characteristics of the sediments have been described by Booth et al. [10]. Dead mangrove leaves from the same area were also sampled. DCs comprise a $70 \mathrm{~mm}$ stainless-steel washer and two polycarbonate membranes with a diameter of $25 \mathrm{~mm}$ and a pore size of $0.03 \mu \mathrm{m}$ (Osmonics). The DC was set up as previously described [4] and all procedures were performed in the sterile environment of a laminar flow hood. Using silicon glue, a sterile membrane filter (pore size, $0.03 \mu \mathrm{m}$ ) was glued to one side of the washer, covering the hole. Sediment and leaf extracts were obtained by mixing sediment or mangrove leaves with MilliQ water in a 1:10 ratio. The mixtures were autoclaved for $30 \mathrm{~min}$, spun down for $10 \mathrm{~min}$ at 11000 r.p.m. and then filter-sterilized using filters with a pore size of $0.22 \mu \mathrm{m}$. These extracts were stored at $4{ }^{\circ} \mathrm{C}$ for further use. The cultivation medium was prepared by diluting $1 \mathrm{~g}$ of fresh mangrove sediments with filtered sea water (FSW) and then mixing it with molten FSW-agar $(1.5 \%)$ and sediment or leaf extracts to a final concentration of $0.1 \%$, reaching a final dilution of $1 \times 10^{4} \mathrm{~g} \mathrm{ml}^{-1}$. Then, $3 \mathrm{ml}$ of this mixture was used to fill the DCs, which were then sealed and incubated in an aquarium containing mangrove sediments and sea water to mimic the natural habitat. After
21 days, the DCs were taken from the aquarium, washed in pure MilliQ water and then opened under a laminar flow hood. The FSW-agar, along with its microbial biomass, was homogenized by passaging it through a sterile syringe with a 25 -gauge needle and then diluted with molten FSW-agar and sediment or leaf extracts to obtain dilutions of $10^{-4}$ to $10^{-6}$ $\mathrm{g} \mathrm{ml}^{-1}$ [47]. The final solution was poured into petri dishes and incubated at $37^{\circ} \mathrm{C}$ for 7 days. Colonies showing growth were collected using glass Pasteur pipettes ( $337 \mathrm{~mm}$ diameter with long tip, Sigma-Aldrich) and subcultured in $0.1 \times$ LuriaBertani (LB) agar supplemented with $0.1 \%$ sediment or leaf extracts. Each isolate was restreaked three times to obtain a pure culture. The purity of the colonies was confirmed using a stereomicroscope (S8AP0; Leica). Bacterial cultures were maintained in marine broth (MB; peptone, $5 \mathrm{~g}$; yeast extract, $1 \mathrm{~g} ; \mathrm{C}_{6} \mathrm{H}_{5} \mathrm{FeO}_{7}, 0.1 \mathrm{~g} ; \mathrm{NaCl}, 19.45 \mathrm{~g} ; \mathrm{MgCl}_{2}, 5.9 \mathrm{~g} ; \mathrm{MgSO}_{4}, 3.24 \mathrm{~g}$; $\mathrm{CaCl}_{2}, 1.8 \mathrm{~g} ; \mathrm{KCl}, 0.55 \mathrm{~g} ; \mathrm{NaHCO}_{3}, 0.16 \mathrm{~g} ; \mathrm{KBr}, 0.08 \mathrm{~g} ; \mathrm{SrCl}_{2}$, $34 \mathrm{mg} ; \mathrm{H}_{3} \mathrm{BO}_{3}, 22 \mathrm{mg} ; \mathrm{Na}_{2} \mathrm{SiO}_{3}, 4 \mathrm{mg} ; \mathrm{NaF}, 2.4 \mathrm{mg} ; \mathrm{NH}_{4} \mathrm{NO}_{3}$, $1.6 \mathrm{mg} ; \mathrm{Na}_{2} \mathrm{HPO}_{4}, 8 \mathrm{mg}$; final salinity using a refractometer, $4 \%)$ at $37^{\circ} \mathrm{C}$. Bacterial culture stocks were further mixed with $30 \%$ glycerol $(\mathrm{v} / \mathrm{v})$ and stored at $-80^{\circ} \mathrm{C}$.

\section{PHYLOGENETIC DIVERSITY OF CULTIVABLE BACTERIA ASSOCIATED WITH MANGROVES}

A total of 55 bacterial strains were isolated and their genomic DNA was extracted by boiling in $50 \mu \mathrm{l}$ of $10 \mathrm{mM}$ sterile Tris- $\mathrm{HCl}$ buffer ( $\mathrm{pH}$ 8.0) [48]. The isolates were phylogenetically identified by amplifying and sequencing the $16 \mathrm{~S}$ rRNA gene. Using universal primer sets, three sets of PCRs were performed. These primer sets amplify three partially overlapping regions of the $16 \mathrm{~S}$ rRNA gene: $27 \mathrm{~F} / 785 \mathrm{R}$ (fragment F1; PCR product of approximately $750 \mathrm{bp}$ ), 341F/907R (F2; approximately $550 \mathrm{bp}$ ) and 785F/1492R (F3; approximately $700 \mathrm{bp}$ ). In a $50 \mu \mathrm{l}$ PCR mix reaction, $0.02 \mathrm{U}_{\mu \mathrm{l}^{-1}}$ (corresponding to $1.0 \mathrm{U}$ per reaction) Taq DNA polymerase (Thermo-Fisher Scientific), $1 \times$ PCR buffer, $1.5 \mathrm{mM} \mathrm{MgCl}_{2}$, $0.2 \mathrm{mM}$ dNTPs mix, $0.3 \mu \mathrm{M}$ of each primer (SIGMA) and 1-3 $\mu$ l template DNA were added. The PCR thermal protocol was as follows: (1) initial denaturation at $94^{\circ} \mathrm{C}$ for $5 \mathrm{~min}$; (2) 30 cycles of denaturation at $94^{\circ} \mathrm{C}$ for $45 \mathrm{~s}$; annealing at 52, 59 and $55^{\circ} \mathrm{C}$ ( $\mathrm{F} 1, \mathrm{~F} 2$ and $\mathrm{F} 3$, respectively) for $1 \mathrm{~min}$; and extension at $72^{\circ} \mathrm{C}$ for $1 \mathrm{~min}$; and (3) final extension at $72^{\circ} \mathrm{C}$ for $10 \mathrm{~min}$. The PCR products were purified using Illustra ExoProStar 1 Step (GE Life Sciences) and sequenced using forward and reverse primers via Sanger sequencing at the Bioscience Core Lab (KAUST). Electropherograms of the sequences were checked for quality, edited and assembled using Geneious v. 8.1.9 (Biomatters) to obtain almost full-length sequences (variable between 1300 and $1450 \mathrm{bp}$ ) of the 16S rRNA gene. The sequences obtained were then compared using the Basic Local Alignment Search Tool (BLAST) algorithm against the reference RNA sequences database (refseq_rna) of the National Centre for Biotechnology Information (NCBI) [49] and the ARB Silva website (https://www.arb-silva.de) [50]. The sequences were submitted to NCBI under the accession numbers MW644816-MW644868. Following the procedures described by de Bruijn et al., enterobacterial repetitive 
Table 1. Taxonomic affiliation of isolated strains obtained using the diffusion chamber with sediment or leaf extracts. Detailed information for the 55 bacterial strains is reported in Table S1. The number of isolates belong to the same group (i.e., clustering of $16 \mathrm{~S}$ rRNA gene sequences at $99 \%$ identity using the vsearch software [52]) is reported; it is followed by the taxonomy and accession number of the most closely related type strains and the range of percentage of identity. Among the isolates within each group, the representative bacterial strain is reported. The entry most closely related to the isolated strain described in this work is indicated in bold type.

\begin{tabular}{|c|c|c|c|}
\hline Number of isolates & Most closely related type strain & Range of percentage identity & Reference isolated strain \\
\hline 5 & Marinobacter adhaerens $\mathrm{HP}^{\mathrm{T}} 5^{\mathrm{T}}$ (NR_074765.1) & $99.17-99.31$ & R1DC51 \\
\hline 3 & Marinobacter salsuginis SD-14B ${ }^{\mathrm{T}}$ (NR_044044.1) & $99.8-100$ & R1DC4 \\
\hline 1 & Microbulbifer celer ISL-39 ${ }^{\mathrm{T}}$ (NR_044243.1) & 98.57 & R1DC56 \\
\hline 1 & Microbulbifer celer ISL-39 ${ }^{\mathrm{T}}$ (NR_044243.1) & 97.7 & R1DC8 \\
\hline 10 & Microbulbifer halophilus YIM $91118^{\mathrm{T}}$ (NR_044351.1) & $98.08-98.34$ & R1DC16 \\
\hline 1 & Muricauda aquimarina SW-63 ${ }^{\mathrm{T}}$ (NR_042909.1) & 98.62 & R1DC39 \\
\hline 1 & Pelagibaca bermudensis HTCC $2601^{\mathrm{T}}$ (NR_043611.1) & 99.72 & R1DC6 \\
\hline 1 & Saccharospirillum salsuginis YIM-Y25 (NR_044132.1) & 97.09 & R1DC57 \\
\hline 2 & Salipiger mucosus A3 ${ }^{\mathrm{T}}$ (NR_029116.1) & 99.63 & R1DC59 \\
\hline
\end{tabular}

intergenic consensus (ERIC) PCR was performed to examine the clonality of the selected strains [51].

The 16S rRNA sequence analyses of the 55 isolates revealed 13 unique bacterial strains after clustering at $99 \%$ using the vsearch software [52]. These strains represented 9 different genera and 11 different species (Tables 1 and S1, Fig. S1a, available in the online version of this article). Among the 55 isolates, we detected two strains, R1DC25 and R1DC58, originating from DCs supplemented with sediment and leaf extracts, respectively, that had identical $16 \mathrm{~S}$ rRNA gene sequences and ERIC PCR patterns (Figs S1b and S2, respectively) as well as $<96 \%$ similarity with a known species of the genus Rhodoligotrophos. (Table 1). On the basis of these results, we selected one of the two strains, $\mathrm{R} 1 \mathrm{DC} 25^{\mathrm{T}}$ for further phylogenetic and physicochemical characterization.

\section{PHYLOGENY BASED ON THE 16 S rRNA GENE AND GENOME SEQUENCES}

The genomic DNA of R1DC25 ${ }^{\mathrm{T}}$ was extracted using a Maxwell RSC Automated Nucleic Acid Purification and Maxwell RSC Cultured Cells DNA kits (Promega). Bacterial cultures were grown at $37^{\circ} \mathrm{C}$ in $\mathrm{MB}$ for $48 \mathrm{~h}$. The extracted DNA was quantified using Qubit dsDNA assay kits with a high sensitivity (Thermo-Fischer Scientific) and via electrophoresis on 1\% agarose gels and qualified using a Bioanalyzer 2100 (Agilent). Genomic DNA was sequenced using a PacBio RS2 sequencer (Pacific Biosciences) at the KAUST Bioscience Core Lab, and the reads were assembled using HGAP.3 workflow analysis [53]. The genome was then annotated using RAST, PROKKA and KEGG analysis for gene function prediction [54-57].
We submitted the complete genome of R1DC25 ${ }^{\mathrm{T}}$ under the GenBank accession number CP058214. The full-length 16S rRNA gene sequence of R1DC $25^{\mathrm{T}}$ was extracted and used for phylogenetic analysis; it was uploaded into GenBank under the accession number MT146881. A phylogenetic tree based on this 16S rRNA gene sequence was reconstructed by the neighbor-joining and maximum-likelihood method using the MEGAX software (v10.1.8). To assess the significance of the generated tree, the topologies of the phylogenetic trees were evaluated using bootstrap analyses based on 1000 resamplings, as described previously [58, 59]. A multilocus sequence analysis (MLSA) or a phylogenomic tree of 120 concatenated single-copy genes obtained from the genome contig of the unclassified isolate was also included to illustrate the existing phylogenetic tree. The GTDB-Tk software (v 1.3) was used to analyse the phylogenetic diversity based on the best BLAST matches for the genes of these markers [60], and a bootstrap analysis of 1000 resamplings was used to evaluate the tree topology [61]. In silico digital DNA-DNA hybridization $(\mathrm{dDDH})$ and BLAST-based average nucleotide identity (ANIb) scores of strains were calculated using the GGDC and JSpeciesWS software, respectively [61, 62], using default parameters. The percentage of conserved proteins (POCP) was also calculated as previously described [63].

Comparison of the 16S rRNA gene sequences indicated that the most closely related species to R1DC $25^{\mathrm{T}}$ were Rhodoligotrophos appendicifer, Rhodoligotrophos jinshengii, and Rhodoligotrophos defluvii, with sequence identities of 95.8, 95.3 and $94.5 \%$, respectively. The $16 \mathrm{~S}$ rRNA gene-based neighbor-joining phylogenetic tree placed R1DC25 $5^{\mathrm{T}}$ away from the three species of the genus Rhodoligotrophos in the 
family Rhodobiaceae (Fig. 1a). Notably, the 16S rRNA gene identity values were only slightly above the threshold for the taxon boundaries of a novel genus ( $<95 \%$ [64]); however, because R1DC $25^{\mathrm{T}}$ formed a separate branch and a novel clade that was different from the type strains of species of the genus Rhodoligotrophos (Fig. 1a), we investigated the phylogenetic placement of R1DC $25^{\mathrm{T}}$ in more detail. A phylogenomic reconstruction based on the MLSA of 120 concatenated conserved bacterial marker genes indicated that R1DC $25^{\mathrm{T}}$ clustered in a group distinct from the genus Rhodoligotrophos (Fig. 1b). When more strains within this family are sequenced, the differences between the Kaustia and Rhodoligotrophos genera will be clarified.

Compared with other identified species within the recently described family Parvibaculaceae, the ANIb was $66-69 \%$ and $\mathrm{dDDH}$ was $18-19 \%$ (Table 2) 46 . The standard ANIb criteria for genus discrimination is $45-65 \%$ and that for species discrimination is 65-95\% [64] and the $\mathrm{dDDH}$ criterion is $70 \%$ for novel species [61]. Accordingly, our data confirmed that R1DC25 ${ }^{\mathrm{T}}$ represents a novel species and possibly a novel genus within the family Parvibaculaceae. POCP has recently been described as valuable for the delineation of the prokaryotic genera (Table 2) [63]. The POCPs of the members of the genus Rhodoligotrophos were slightly above $50 \%$, which is the recommended threshold for genus delimitation. However, the thresholds for the definition of novel genera, i.e., 16S rRNA gene identity, ANIb and POCP values [63, 64], are approximate, and both phylogenetic trees indicated that R1DC25 ${ }^{\mathrm{T}}$ is clearly separated from the members of the genus Rhodoligotrophos. Therefore, we propose that R1DC $25^{\mathrm{T}}$ represents a member of a novel genus. In addition, only two species were available within the genus Rhodoligotrophos, and all other members of the family Parvibaculaceae are phylogenetically distant from R1DC25 $5^{\mathrm{T}}$. The sequencing of more genomes in this group will enable us to elucidate the phylogenetic separation between R1DC2 $5^{\mathrm{T}}$ and members of the genus Rhodoligotrophos.

The genome length of R1DC2 $25^{\mathrm{T}}$ is $4.63 \mathrm{Mb}$, with a DNA $\mathrm{G}+\mathrm{C}$ content of $67.3 \mathrm{~mol} \%$ (Fig. S3). The genome was assembled in one contig comprising 4438 genes; of these, 4384 are protein-coding sequences and 54 are RNA-coding sequences. The genome includes two copies of the $16 \mathrm{~S}$ rRNA gene ( $1522 \mathrm{bp}$ ) and 50 copies of tRNA. Of all protein-coding genes, $67 \%$ were assigned a putative function, whereas the remaining genes were annotated as hypothetical proteins (Fig. S3). The presence of respiratory lipoquinones, cytochrome oxidases and membrane-bound electron transport chainencoding genes confirmed that this strain is aerobic and can use oxygen as a terminal electron acceptor for respiration. However, this strain also possesses genes related to oxygen limitation (Table S2), such as the transporter system fixLJK [65], which allows resistance to the low-oxygen conditions of mangrove sediments $[10,66,67]$. Additionally, genome analysis confirmed the presence of genes encoding for osmoprotectant biosynthesis or transport (Table S2), such as the genes for proline (proABC, HW532_13700, HW532_17195 and HW532_137005), ectoine (lysC, HW532_10325) and betaine and choline (betA, HW532_01520) and for a glycine betaine/proline transport system (proVWX, HW532_0585060 ), as well as genes associated with the synthesis of phytoene, a carotenoid precursor, via the nonmevalonate pathway. These compounds are used by R1DC $25^{\mathrm{T}}$ to adapt to the conditions of osmotic stress and the harsh mangrove environment $[8,10,68]$, thus allowing survival in the salty sediments of the mangroves, where salinity can reach $15 \%$ in summer [10]. The basic nature of the proteome, which has an average isoelectric point of 6.63, is similar to that of Desulfohalobium retbaense (6.5), a halophilic strain that uses the same osmoprotective mechanisms [69].

In addition to its capacity to survive the salinity and osmotic stress of the Red Sea mangrove sediments, R1DC25 $5^{\mathrm{T}}$ is able to survive the oligotrophic conditions of the mangrove forest [68]. This is partly because it possesses all the genes associated with the biosynthesis of amino acids and many transporters, such as phoBDR, $g \ln A G L$ and $n \operatorname{tr} Y X$, that can be activated in case of nutrient limitation (Table S2). These transporters are important for survival under limited phosphate and nitrogen conditions [70-72]. However, nifA, which is responsible for nitrogen fixation, was not found, although it is normally regulated by the $n t r Y X$ transporter [71]. We also identified the presence of several genes involved in antibiotic resistance, particularly to beta-lactam and vancomycin, which may explain the resistance of the organism to a relatively large number of antibiotics as observed in in vitro tests conducted with Phenotype Microarray Biolog PM11 and PM12 plates described in the section on morphological, physiological and chemotaxonomic characterization.

As mangrove sediments, the environment of origin of R1DC25 $5^{\mathrm{T}}$, are dominated by plants and their widespread roots, we also investigated at the genome level the potential of this strain to interact with plants and promote plant growth. R1DC $25^{\mathrm{T}}$ does not possesses the complete pathways for flagellar biosynthesis, chemotaxis, root surface adhesion, quorum sensing or biofilm formation, which indicates that its lifestyle does not include a physical association with plant roots [73]. However, several genes encoding phytohormone production were identified, including those coding for 1-amin ocyclopropane-1-carboxylic acid deaminase (HW532_02305) and auxin [indole acetic acid (IAA); nthAB, HW532_05650, HW532_05645] (Table S2). These results indicate the existence of a possible beneficial relationship between R1DC $25^{\mathrm{T}}$ and mangrove plants, which is mediated via a phytohormone homeostasis mechanism that positively affects mangroves, particularly during stressful conditions, such as drought and salinity, as previously observed in other natural and induced stress conditions [74-79]. Genes involved in biofertilization activity were also detected (Table S2). Among these were genes coding for the siderophore aerobactin (iucABCD, HW532_05380-95), which chelates iron and increases its availability to other macroorganisms and microorganisms [80-82] and competes as well for iron with possible plant pathogens [81]. Genome analysis revealed nitrate-reducing capacity involving narGHI, HW532_11500-15 (Table S2). This reaction is a major source of nitrogen for plant development 
(a)
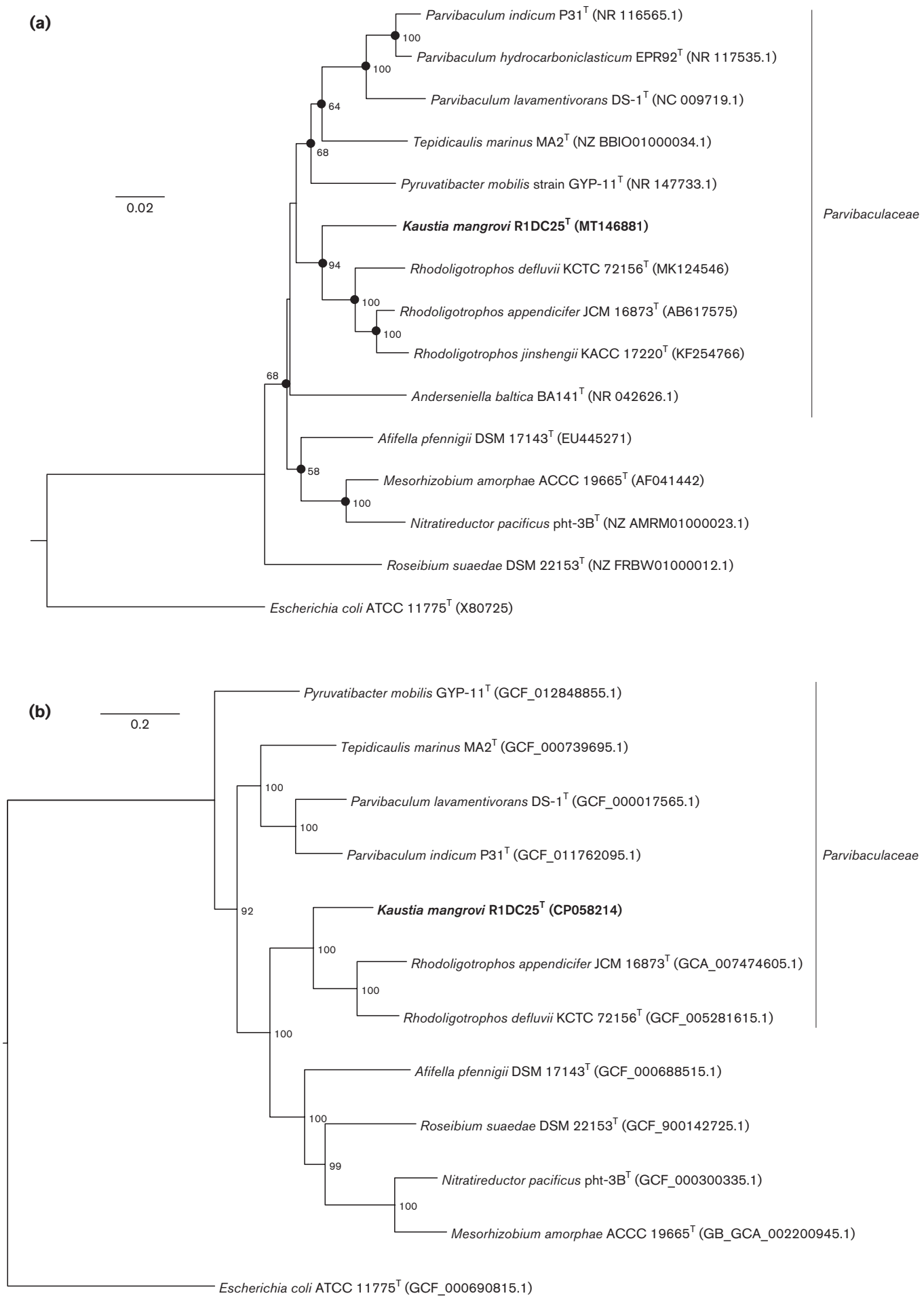

Fig. 1. (a) Neighbor-joining phylogenetic tree based on $16 \mathrm{~S}$ rRNA gene sequences showing the position of Kaustia mangrovi R1DC25 (MT146881). Only bootstrap values (expressed as percentages of 1000 replications) of $>50 \%$ are shown at the branching points. Filled circles indicate branches that were also recovered using the maximum-likelihood method. Escherichia coli ATCC $11775^{\top}$ (GenBank accession number X80725) was used as an outgroup. Bar, 0.020 substitutions per nucleotide position. The families of the different strains are shown on the right of the phylogenetic tree (b) Neighbor-joining phylogenomic tree using a MLSA concatenating 120 essential single-copy genes, highlighting the position of R1DC25T relative to other closely related bacterial taxa within the order Rhizobiales. The tree was reconstructed using the software GTDB-Tk [60]. Numbers at the nodes designate bootstrap support values resulting from 1000 bootstrap replicates. Bar, 0.2 substitution per nucleotide position. Strains within family Parvibaculaceae are indicated by a vertical line. 
Table 2. Average nucleotide identity via BLAST (ANIb) and percentage of aligned sequences in brackets, using in silico digital DNA-DNA hybridization $(\mathrm{dDDH})$ and percentage of conserved proteins (POCP) matrix of isolate K. mangrovi R1DC25 ${ }^{\top}$ with other representatives of the family Parvibaculaceae. The cut-off percentages to be assigned to the same species are $\geq 95 \%$ and $\geq 70 \%$ for ANIb and dDDH, respectively; the cut-off percentage to be assigned to the same genus is $\geq 50 \%$ for POCP

\begin{tabular}{|c|c|c|c|}
\hline Reference genome & ANIb (\%) & dDDH (\%) & POCP (\%) \\
\hline Rhodoligotrophos sp. $\operatorname{lm} 1^{\mathrm{T}}$ & $69.2[30.7]$ & 18.7 & 54.7 \\
\hline Tepidamorphus gemmatus DSM $19345^{\mathrm{T}}$ & $69.6[27.7]$ & 18.6 & 51.4 \\
\hline Lutibaculum baratangense $\mathrm{AMV}^{\mathrm{T}}$ & $69.2[28.4]$ & 18.5 & 49.8 \\
\hline Mesorhizobium tamadayense DSM $28320^{\mathrm{T}}$ & $68.9[25.5]$ & 18.1 & 41.8 \\
\hline Parvibaculum lavamentivorans $\mathrm{DS}-\mathrm{1}^{\mathrm{T}}$ & $68.7[20.0]$ & 18.3 & 42.0 \\
\hline Bauldia litoralis ATCC $35022^{\mathrm{T}}$ & $68.7[24.9]$ & 18.5 & 43.3 \\
\hline Dichotomicrobium thermohalophilum DSM $5002^{\mathrm{T}}$ & $68.5[21.9]$ & 18.2 & 46.8 \\
\hline Oricola cellulosilytica CC-AMH- $0^{\mathrm{T}}$ & $67.4[20.1]$ & 18.3 & 44.6 \\
\hline Phyllobacterium endophyticum PEPV $15^{\mathrm{T}}$ & $66.7[19.5]$ & 18.6 & 43.2 \\
\hline
\end{tabular}

and is also a limiting factor for mangrove growth in the oligotrophic conditions of the Red Sea coast [68]. These results strongly indicate that R1DC $25^{\mathrm{T}}$ is not directly or physically associated with the mangrove plants but can indirectly influence plant growth and fitness by acting as plant biofertilizer, growth biopromoter and pathogen biocontrol agent.

\section{MORPHOLOGICAL, PHYSIOLOGICAL AND CHEMOTAXONOMIC CHARACTERIZATION}

Cell morphology was examined using scanning electron microscopy [Teneo SEM (FEI)] at the Imaging Core Lab at KAUST. Motility was determined using semisolid $0.3 \% \mathrm{MB}$ agar. To determine the temperature range for growth, the strain was grown in $50 \mathrm{ml} \mathrm{MB}$ and incubated at temperatures of $10,20,30,37,40$ and $50^{\circ} \mathrm{C}$ ( $n=3$ per temperature). $\mathrm{OD}_{600}$ was measured using a UV-1600PC spectrophotometer (VWR) every $12 \mathrm{~h}$ for 3 days. To evaluate the organism's capacity to grow in the presence of salt, $\mathrm{MB}$ medium was prepared (recipe reported in the isolation and habitat section) but without salts. The salinity was $<1 \%$ as measured by a portable salinity refractometer; we considered this as $0 \%$ salinity. Different concentrations of $\mathrm{NaCl}, 0-19 \%$, were added to the modified medium with $1 \%$ as the incremental step and cultures were grown by incubating at $37^{\circ} \mathrm{C} . \mathrm{OD}_{600}$ of the cultures were measured using a UV-1600PC spectrophotometer at intervals of $12 \mathrm{~h}$ using non-inoculated media as the control. Further physiological and phenotypic characterization was performed using the Phenotype Microarray Biolog plates, and growth was investigated in the presence of different $\mathrm{pH}$ values (PM10) and sensitivity to antibiotics (PM11 and PM12 plates) using standard $\mathrm{MB}$ according to the manufacturers' instructions. In case of PM9, wherein osmolytes and ions were present, bacterial cells were inoculated in the IF10 medium provided by Biolog, a rich medium with $0 \%$ salinity. Carbon utilization was tested using the Phenotype Microarray Biolog plates (PM1 and PM2). To inoculate these plates, modified $\mathrm{MB}$ was prepared as previously reported but without adding peptone and yeast extract.

The oxidase activity of R1DC25 $5^{\mathrm{T}}$ was tested using oxidase strips (Sigma-Aldrich), and catalase activity was determined by bubble formation in $3 \%(\mathrm{v} / \mathrm{v})$ hydrogen peroxide solution [83]. Indole production was tested according to the method described by Bric et al. [84], and nitrate reducing ability was examined using nitrate reduction kits (Sigma) as per the manufacturers' instructions. Nitrate broth medium was modified and supplemented with $4 \% \mathrm{NaCl}$. Screening for enzyme activity was performed as described by Liu et al. [85] using MB agar plates to measure the activities of amylase, protease, lipase and cellulase. Furthermore, cellular fatty acids, respiratory quinones and polar lipids were analysed using the identification service laboratories of DSMZ (Braunschweig, Germany) for chemotaxonomic determination [86-88].

The novel strain R1DC25 $5^{\mathrm{T}}$ was Gram-stain-negative, aerobic or facultatively anaerobic, non-motile and non-sporulating. Colonies were circular, with a diameter of $0.2-0.5 \mathrm{~mm}$, smooth, shiny, with regular edges and of a creamy colour. Scanning electron microscopy of the colony-forming cells showed irregular coccoid cells $0.5-1 \mu \mathrm{m}$ in diameter (Fig. 2a, b) with thin surface appendages (Fig. 2b, c) [89]. These appendages appeared to be implicated in surface adhesion 


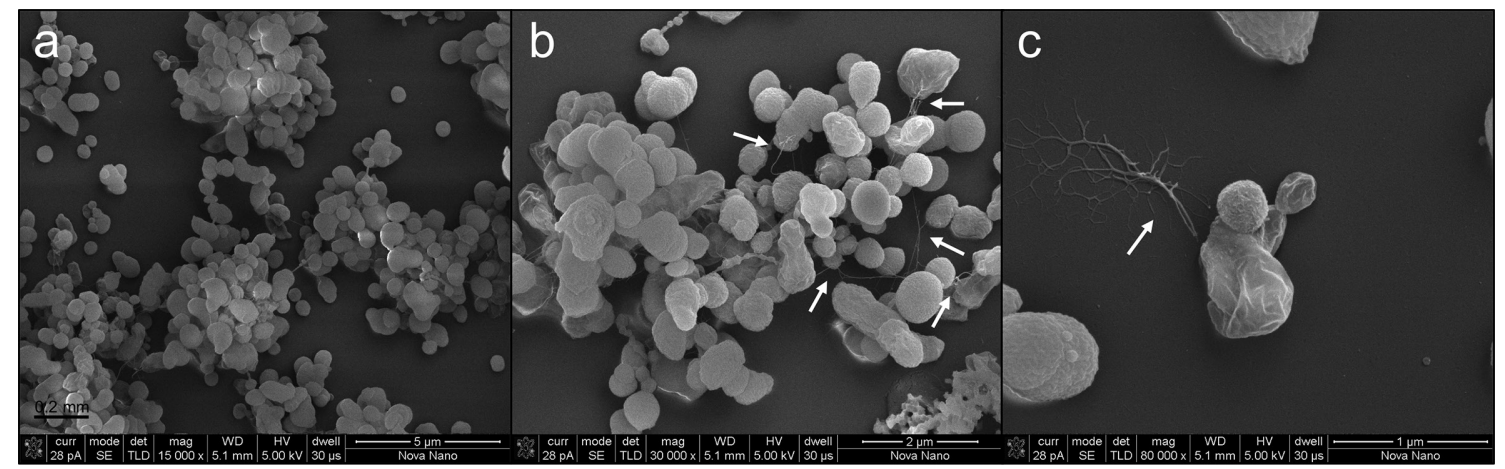

Fig. 2. (a-c) Scanning electron micrographs of Kaustia mangrovi R1DC25 cells grown on MB medium after $48 \mathrm{~h}$ of incubation at $37^{\circ} \mathrm{C}$. Bars' lengths are 5, 2 and $1 \mu \mathrm{m}$, respectively; arrows indicate the bacterial appendages outward from the surface of R1DC25 cells.

(Fig. 2c) and possibly in bacterium-bacterium interactions during biofilm formation in the microbial mats [89].

R1DC2 $5^{\mathrm{T}}$ is a mesophilic bacterium that can grow between temperatures of a5 and $40^{\circ} \mathrm{C}$, with optimum temperature between 30 and $40^{\circ} \mathrm{C}$ (Fig. S4a). The doubling time under optimum conditions at $37^{\circ} \mathrm{C}$ was estimated as $5.2 \mathrm{~h}$. It was able to grow in medium containing $2-14 \% \mathrm{NaCl}$, with optimal growth at 3-5\% (Fig. S4b). These optimal conditions indicate that the strain is adapted to the salinity of the mangrove sediments in the Red Sea where no fresh water inputs occur and salinity can reach up to $15 \%$ during summer [10]. The $\mathrm{OD}_{600}$ of $\mathrm{R} 1 \mathrm{DC} 25^{\mathrm{T}}$ grown in $\mathrm{MB}$ with $\mathrm{NaCl}$ as the only salt was less than that of those grown using a mixture of salts $\left(\mathrm{MgCl}_{2}, \mathrm{Na}_{2} \mathrm{SO}_{4}, \mathrm{CaCl}_{2}\right.$ and $\left.\mathrm{KCl}\right)$ (Fig. S4b). This preference may indicate a strong dependence of R1DC $25^{\mathrm{T}}$ on sea salts. The results of PM9 Biolog plate experiments indicated that R1DC2 $5^{\mathrm{T}}$ is metabolically active. We measured the production of NADH in the presence of different osmolytes and ions, such as ectoine, betaine, proline, glycerol, sodium sulphate and sodium nitrate (Table S3), and the results revealed that the organism has the ability to osmoadapt under these conditions. Bacterial metabolism was inhibited in the presence of potassium chloride, ethylene glycol, sodium formate, urea, sodium lactate, sodium phosphate, sodium benzoate, ammonium sulphate and sodium nitrite (Table S3). R1DC $25^{\mathrm{T}}$ could grow at $\mathrm{pH}$ values ranging between 6 and 10, with optimum growth at $\mathrm{pH} 8.5$ (Fig. S4c). These findings were in accordance with its environment of origin, where the $\mathrm{pH}$ of the sediments varied from 7.5 to 10 over the course of the year (Fusi, personal communication).

R1DC25 $5^{\mathrm{T}}$ is catalase-negative and oxidase-positive, and it can reduce nitrate to nitrite. The cells are negative for amylase, protease, lipase and cellulase and positive for the production of ammonia and IAA from tryptophan (Table 3). Of the 190 carbon sources available in the PM1 and PM2 plates, the strain showed active growth in the presence of 30 carbon sources (Table S4). Among these, 16 carbon sources showed strongly positive results, i.e., twice that of the negative control, whereas the remaining 14 produced a weakly positive respiration with slower metabolism and growth (Table S4).
The predominant respiratory quinone of $\mathrm{R} 1 \mathrm{DC} 25^{\mathrm{T}}$ was ubiquinone Q-10 (100\%) as seen in many members of the class Alphaproteobacteria [89]. The cellular fatty acids of R1DC $25^{\mathrm{T}}$ are composed of $\mathrm{C}_{19: 0}$ cyclo $\omega 8 c$, a combination of $\mathrm{C}_{18: 1} \omega 7 c$ and/or $\mathrm{C}_{18: 1} \omega 6 c$ and $\mathrm{C}_{16: 0}$ (Table S5). This was consistent with the results of the phylogenetic analysis and confirmed the separate taxonomic status of the novel isolate [90]. R1DC25 ${ }^{\mathrm{T}}$ was clearly distinguished from other species of the genus Rhodoligotrophos due to the predominance of a combination of unsaturated chain fatty acids, cyclo- $\mathrm{C}_{19: 0} \omega 8 c(47.54 \%)$, and straight chain saturated fatty acids, $\mathrm{C}_{16: 0}(15.54 \%)$ with the presence of $\mathrm{C}_{18: 1} \omega 7 c$ and/or $\mathrm{C}_{18: 1} \omega 6 c$ (summed feature 8; $20.71 \%$ ), which have not been detected in members of the genus Rhodoligotrophos. The proportion of cyclo- $\mathrm{C}_{19: 0} \omega 8 \mathrm{c}$ was higher in R1DC25 than in other related species, and, in contrast to the related species, the methylated fatty acids 11 methyl- $\mathrm{C}_{18: 1} \omega 7 c$ and 10 methyl- $\mathrm{C}_{19: 0}$ were present in R1DC25 and $\mathrm{C}_{18: 1} \omega 9 c$ and branched saturated chain fatty acids were absent (Table S5). The cellular fatty acid composition may change depending on the medium in which cells have been grown, and the comparison of the fatty acids of R1DC $25^{\mathrm{T}}$ with published descriptions of fatty acids of the strains of members of the genus Rhodoligotrophos should be taken with caution; however, the differences observed among the fatty acids (31-49\% of fatty acids) support the classification of $\mathrm{R} 1 \mathrm{DC} 25^{\mathrm{T}}$ as a representative of a novel genus. The polar lipids are phosphatidylglycerol, phosphatidylcholine, diphosphatidylglycerol, several distinct aminolipids, three unidentified aminolipids and two unidentified lipids (Table 3). This profile was different from those of the other species of the genus Rhodoligotrophos because of the absence of phosphatidylethanolamine, glycolipid and five unknown lipids.

Overall, chemotaxonomic characterization indicated that R1DC2 $5^{\mathrm{T}}$ is distinct from the most closely related species within the genus Rhodoligotrophos (Table 3), and it can be also differentiated from the phylogenetically closely related genera within the family Rhodobiaceae (Table S6), supporting its classification as a member of a novel genus.

On the basis of data obtained from a polyphasic approach, strain R1DC2 $5^{\mathrm{T}}$ represents a novel species of the novel genus 
Table 3. General features and genomic and phenotypic characteristics of R1DC25 and closely related members of the genus Rhodoligotrophos Strains: 1, K. mangrovi R1DC25 (data from this study); 2, R. appendicifer JCM 16873 (data from [89] 90); 3, R. jinshengii BUT-3 ${ }^{\top}$ (data from [91]);

4, R. defluvii $\operatorname{lm} 1^{\top}$ (data from [85] 60). +, Positive; -, negative; NA, not available.

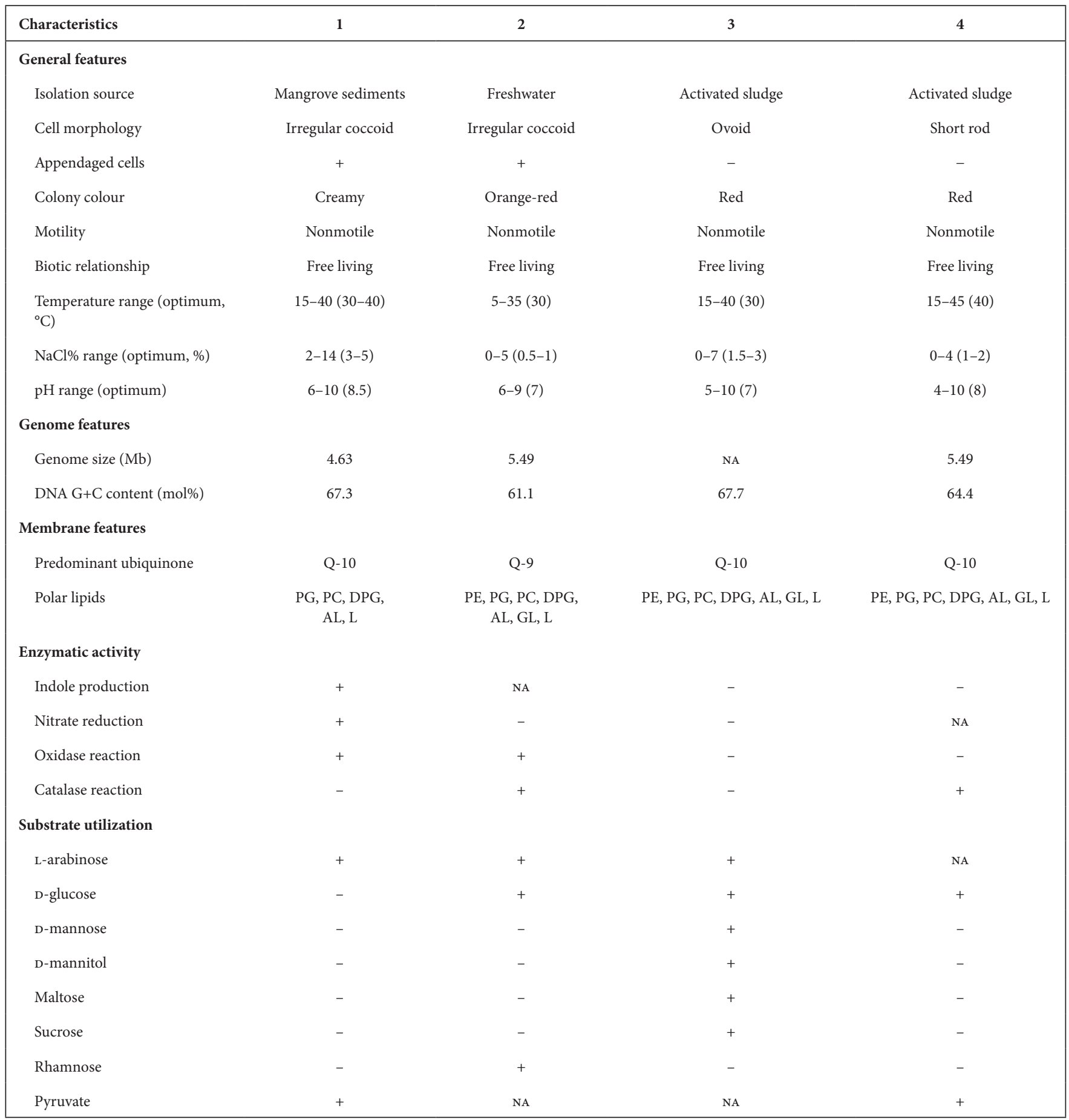

AL, Alabaster; DPG, Diphosphotidyglycerol; GL, Glycolipid; L, Lipid; PC, Phosphatidylcholines; PE, Phosphatidylethanolamine; PG, Phosphatidylglycerol. 
in the Rhodobiaceae, for which the name Kaustia mangrovi gen. nov., sp. nov. is proposed.

\section{DESCRIPTION OF KAUSTIA GEN. NOV.}

Kaustia [Kaus'ti.a. N.L. fem. n. Kaustia subjective name derived from the abbreviation KAUST (King Abdullah University of Science and Technology)].

The bacterial cells are Gram-stain-negative, aerobic/ facultatively anaerobic, moderately halophilic, mesophilic, non-motile, non-sporulating, catalase-negative, oxidasepositive and nitrate-reduction-positive. The cellular fatty acids included significant amounts $(>5 \%)$ of $\mathrm{C}_{19: 0}$ cyclo $\omega 8 \mathrm{c}$, a combination of $\mathrm{C}_{18: 1} \omega 7 c$ and/or $\mathrm{C}_{18: 1} \omega 6 c$ and $\mathrm{C}_{16: 0}$. Ubiquinone Q-10 (100\%) is the major respiratory quinone. The polar lipid composition is dominated by phosphatidylglycerol, phosphatidylcholine and diphosphatidylglycerol, as well as several distinct aminolipids and lipids.

The type species is Kaustia mangrovi.

\section{DESCRIPTION OF KAUSTIA MANGROVI SP. NOV.}

Kaustia mangrovi (man.gro'vi. N.L. gen. n. mangrovi of a mangrove).

Colonies are circular and creamy in colour and measure $0.8 \mu \mathrm{m}$ in diameter. Growth occurs at $2-14 \% \mathrm{NaCl}$ (optimum, $3-5 \%$ ), $15-40{ }^{\circ} \mathrm{C}$ (optimum, $30-40^{\circ} \mathrm{C}$ ) and a $\mathrm{pH}$ of $6.5-10$ (optimum, 8.5). Can grow in the presence of several osmolytes and ions at different concentrations. Cells are positive for the production of indole and ammonia from tryptophan, but are negative for amylase, protease, lipase and cellulase activity. The following substrates are used: $\mathrm{L}$-arabinose, $\mathrm{D}$-arabinose, D-glucosamine, D-saccharinic acid, dihydroxy acetone, L-alaninamide, L-alanine, L-asparagine, L-glutamic acid, L-glutamine, L-ornithine, L-proline, mucic acid, oxalomalic acid, pyruvic acid, 5-keto-D-gluconic acid and pyruvate.

The type strain is $\mathrm{R} 1 \mathrm{DC} 25^{\mathrm{T}} \quad\left(=\mathrm{KCTC} \quad 72348^{\mathrm{T}}=\mathrm{JCM}\right.$ $33619^{\mathrm{T}}=$ NCCB $\left.100699^{\mathrm{T}}\right)$ isolated from the mangrove sediments on the coast of the Red Sea in KAUST (Thuwal, Saudi Arabia). The genome of the type strain has a size of $4.63 \mathrm{Mb}$ and a DNA G+C content of $67.3 \mathrm{~mol} \%$. The GenBank accession number for the 16S rRNA gene sequence of strain R1DC9 ${ }^{\mathrm{T}}$ extracted from the genome DNA sequence is MT146883. The whole-genome shotgun sequence project was deposited at DDBJ/EMBL/GenBank under the following accession identification: CP028923.1.

\section{Funding information}

This research was funded by King Abdullah University of Science and Technology (KAUST) as part of the Circular Carbon Economy initiative (grant number, REI/1/4483-01-01) and the Competitive Research Grant 'Microlanding. The role of the bacterial symbiome at the gill-water (air) interface in the evolution toward terrestrialization' (grant number, CRG-7-3739)".
Acknowledgements

We thank Sadaf Umer and Taskeen Begum for her support in organizing the laboratory work.

Conflicts of interest

The authors declare that there are no conflicts of interest.

References

1. Prakash O, Shouche Y, Jangid K, Kostka JE. Microbial cultivation and the role of microbial resource centers in the omics era. Appl Microbiol Biotechnol 2013;97:51-62.

2. Jousset A, Bienhold C, Chatzinotas A, Gallien L, Gobet A et al. Where less may be more: how the rare biosphere pulls ecosystems strings. Isme J 2017;11:853-862.

3. Lewis WH, Tahon G, Geesink P, Sousa DZ, Ettema TJG. Innovations to culturing the uncultured microbial majority. Nat Rev Microbiol 2020:1-16.

4. Kaeberlein T, Lewis K, Epstein SS. Isolating "uncultivable" microorganisms in pure culture in a simulated natural environment. Science 2002;296:1127-1129.

5. Bollmann A, Lewis K, Epstein SS. Incubation of environmental samples in a diffusion chamber increases the diversity of recovered isolates. Appl Environ Microbiol 2007;73:6386-6390.

6. Donato DC, Kauffman JB, Murdiyarso D, Kurnianto S, Stidham M. Mangroves among the most carbon-rich forests in the tropics. Nat Geosci 2011:4:293-297.

7. Thatoi H, Behera BC, Mishra RR, Dutta SK. Biodiversity and biotechnological potential of microorganisms from mangrove ecosystems: a review. Annals of Microbiology 2013;63:1-19.

8. Arshad M, Eid EM, Hasan M. Mangrove health along the hyperarid southern Red Sea coast of Saudi Arabia. Environ Monit Assess 2020;192:189

9. Giomi F, Barausse A, Duarte CM, Booth J, Agusti S et al. Oxygen supersaturation protects coastal marine fauna from ocean warming. Sci Adv 2019;5:eaax1814.

10. Booth JM, Fusi M, Marasco R, Mbobo T, Daffonchio D. Fiddler crab bioturbation determines consistent changes in bacterial communities across contrasting environmental conditions. Sci Rep 2019:9:3749.

11. Booth JM, Fusi M, Marasco R, Michoud G, Fodelianakis S et al. The role of fungi in heterogeneous sediment microbial networks. Sci Rep 2019;9:7537.

12. Allard SM, Costa MT, Bulseco AN, Helfer V, Wilkins LGE et al. Introducing the mangrove microbiome initiative: identifying microbial research priorities and approaches to better understand, protect, and rehabilitate mangrove ecosystems. mSystems 2020;5:1-9.

13. Alongi DM. Mangrove-microbe-soil relations. In: Kristensen E, Haese RR, Kostka JE (editors). Interactions Between Macro- and Microorganisms in Marine Sediments; 2013. pp. 85-103.

14. Mendes L, Tsai S. Variations of bacterial community structure and composition in mangrove sediment at different depths in southeastern Brazil. Diversity 2014;6:827-843.

15. Das A, Bhattacharya S, Mohammed AYH, Rajan SS. In vitro antimicrobial activity and characterization of mangrove isolates of streptomycetes effective against bacteria and fungi of nosocomial origin. Brazilian Arch Biol Technol 2014:57:349-356.

16. Bhattacharyya D, Garladinne M, Lee YH. Volatile indole produced by rhizobacterium Proteus vulgaris JBLS202 stimulates growth of Arabidopsis thaliana through auxin, cytokinin, and brassinosteroid pathways. J Plant Growth Regul 2014:34:158-168.

17. Lin $X$, Hetharua $B$, Lin L, Xu H, Zheng T et al. Mangrove sediment microbiome: adaptive microbial assemblages and their routed biogeochemical processes in Yunxiao mangrove national nature reserve, China. Microb Ecol 2019;78:57-69.

18. Nathan VK, Vijayan J, Ammini P. Comparison of bacterial diversity from two mangrove ecosystems from India through metagenomic sequencing: comparative mangrove bacterial diversity using metagenomics. Reg Stud Mar Sci 2020;35:101184. 
19. Sengupta S, Pramanik A, Nag S, Roy D, Bhattacharyya A. Microbial diversity and related secondary metabolite gene assortment at an estuarine mangrove ecosystem. Reg Stud Mar Sci 2020;34:101051.

20. Ceccon DM, Faoro H, Lana PdaC, Souza EMde, Pedrosa FdeO. Metataxonomic and metagenomic analysis of mangrove microbiomes reveals community patterns driven by salinity and $\mathrm{pH}$ gradients in Paranaguá Bay, Brazil. Sci Total Environ 2019;694:133609.

21. Haldar S, Nazareth SW. Taxonomic diversity of bacteria from mangrove sediments of Goa: metagenomic and functional analysis. 3 Biotech 2018;8:436.

22. Alongi DM. Bacterial productivity and microbial biomass in tropical mangrove sediments. Microb Ecol 1988;15:59-79.

23. Zhang $X, H u$ BX, Ren $H$, Zhang J. Composition and functional diversity of microbial community across a mangrove-inhabited mudflat as revealed by $16 \mathrm{~S}$ rDNA gene sequences. Sci Total Environ 2018;633:518-528.

24. Michelato Ghizelini A. Microbial diversity in Brazilian mangrove sediments - A mini review. Brazilian J Microbiol 2012;43:1242-1254.

25. Santana CO, Melo VM, Jesus TB, Chinalia FA. Microbial community structure and ecology in sediments of a pristine mangrove forest. bioRxiv 2019:814-833.

26. Gong B, Cao H, Peng C, Perčulija V, Tong G et al. High-throughput sequencing and analysis of microbial communities in the mangrove swamps along the coast of Beibu Gulf in Guangxi, China. Sci Rep 2019:9:9377.

27. Ser HL, Tan WS, Ab Mutalib NS, Yin WF, Chan KG et al. Draft genome sequence of mangrove-derived Streptomyces sp. MUSC 125 with antioxidant potential. Front Microbiol 2016;7:1470

28. Lee GH, Rhee MS, Chang DH, Kwon KK, Bae KS et al. Bacillus solimangrovi sp. nov., isolated from mangrove soil. Int J Syst Evol Microbiol 2014:64:1622-1628.

29. Mo K, Huang H, Bao S, Hu Y. Bacillus caeni sp. nov., isolated from mangrove sediment. Int J Syst Evol Microbiol 2020;70:1503-1507.

30. JWF L, Ser HL, Ab Mutalib NS, Saokaew S, Duangjai A. Streptomyces monashensis sp. nov., a novel mangrove soil actinobacterium from East Malaysia with antioxidative potential. Sci Rep 2019:9:1-18.

31. Ren $\mathrm{H}, \mathrm{Ma} \mathrm{H}, \mathrm{Li} \mathrm{H}$, Huang L, Luo Y. Acidimangrovimonas sediminis gen. nov., sp. nov., isolated from mangrove sediment and reclassification of Defluviimonas indica as Acidimangrovimonas indica comb. nov. and Defluviimonas pyrenivorans as Acidimangrovimonas pyrenivorans comb. nov. Int J Syst Evol Microbiol 2019;69:2445-2451

32. Zheng S, Zhang D, Gui J, Wang J, Zhu X et al. Thalassotalea mangrovi sp. nov., a bacterium isolated from marine mangrove sediment. Int J Syst Evol Microbiol 2019:69:3644-3649.

33. Zhang D, Gui J, Zheng S, Zhu X, Wu S et al. Marisediminitalea mangrovi gen. nov., sp. nov., isolated from marine mangrove sediment, and reclassification of Aestuariibacter aggregatus as Marisediminitalea aggregata comb. nov. Int J Syst Evol Microbiol 2020;70:457-464.

34. An S-Y, Kanoh K, Kasai H, Goto K, Yokota A. Halobacillus faecis sp. nov., a spore-forming bacterium isolated from a mangrove area on Ishigaki Island, Japan. Int J Syst Evol Microbiol 2007;57:2476-2479.

35. Lee LH, Azman AS, Zainal N, Eng SK, Mutalib NS et al. Microbacterium mangrovi sp. nov., an amylolytic actinobacterium isolated from mangrove forest soil. Int J Syst Evol Microbiol 2014;64:3513-3519.

36. Lee LH, Azman AS, Zainal N, Eng SK, Fang CM et al. Novosphingobium malaysiense $\mathrm{sp}$. nov. isolated from mangrove sediment. Int J Syst Evol Microbiol 2014;64:1194-1201.

37. Chen WM, Li Y-S, Young C-C, Sheu S-Y. Paracoccus mangrovi sp. nov., isolated from a mangrove. Int J Syst Evol Microbiol 2017;67:2689-2695.

38. Gao ZM, Xiao J, Wang XN, Ruan LW, Chen XL et al. Vibrio xiamenensis sp. nov., a cellulase-producing bacterium isolated from mangrove soil. Int J Syst Evol Microbiol 2012;62:1958-1962.
39. Zhao C, Gao Z, Qin Q, Ruan L. Mangroviflexus xiamenensis gen. nov. sp. nov., a member of the family Marinilabiliaceae isolated from mangrove sediment. Int J Syst Evol Microbiol 2012;62:1819-1824.

40. Huang XF, Liu YJ, Dong J-D, Qu L-Y, Zhang Y-Y et al. Mangrovibacterium diazotrophicum gen. nov., sp. nov., a nitrogen-fixing bacterium isolated from a mangrove sediment, and proposal of Prolixibacteraceae fam. nov. Int J Syst Evol Microbiol 2014;64:875-881.

41. Yu Z, Cao Y, Zhou G, Yin J, Qiu J. Mangrovicoccus ximenensis gen. nov., sp. nov., isolated from mangrove forest sediment. Int J Syst Evol Microbiol 2018;68:2172-2177.

42. Liao H, Li Y, Guo X, Lin X, Lai Q et al. Mangrovitalea sediminis gen. nov., sp. nov., a member of the family Alteromonadaceae isolated from mangrove sediment. Int J Syst Evol Microbiol 2017;67:5172-5178.

43. Li Y, Bai S, Yang C, Lai Q, Zhang $\mathrm{H}$ et al. Mangrovimonas yunxiaonensis gen. nov., sp. nov., isolated from mangrove sediment. Int J Syst Evol Microbiol 2013;63:2043-2048.

44. Liao H, Li Y, Lin X, Lai Q, Tian Y. Zhengella mangrovi gen. nov., sp. nov., a novel member of family Phyllobacteriaceae isolated from mangrove sediment. Int J Syst Evol Microbiol 2018;68:2819-2825.

45. Hördt A, López MG, Meier-Kolthoff JP, Schleuning M, Weinhold LM et al. Analysis of 1,000+ type-strain genomes substantially improves taxonomic classification of Alphaproteobacteria. Front Microbiol 2020;11:468.

46. Erlacher A, Cernava T, Cardinale M, Soh J, Sensen CW et al. Rhizobiales as functional and endosymbiontic members in the lichen symbiosis of Lobaria pulmonaria L. Front Microbiol 2015;6:53.

47. Bollmann A, Palumbo AV, Lewis K, Epstein SS. Isolation and physiology of bacteria from contaminated subsurface sediments. Appl Environ Microbiol 2010;76:7413-7419.

48. Marasco R, Rolli E, Ettoumi B, Vigani G, Mapelli F et al. A drought resistance-promoting microbiome is selected by root system under desert farming. PLoS One 2012;7:e48479.

49. Agarwala R, Barrett T, Beck J, Benson DA, Bollin C et al. Database resources of the National Center for Biotechnology Information. Nucleic Acids Res 2016:44:D7-D19.

50. Quast C, Pruesse E, Yilmaz P, Gerken J, Schweer T et al. The SILVA ribosomal RNA gene database project: improved data processing and web-based tools. Nucleic Acids Res 2013;41:D590-D596.

51. de Bruijn FJ. Use of repetitive (repetitive extragenic palindromic and enterobacterial repetitive intergeneric consensus) sequences and the polymerase chain reaction to fingerprint the genomes of Rhizobium meliloti isolates and other soil bacteria. Appl Environ Microbiol 1992;58:2180-2187.

52. Rognes T, Flouri T, Nichols B, Quince $C$, Mahé F. VSEARCH: a versatile open source tool for metagenomics. PeerJ 2016;4:e2584.

53. Chin C-S, Alexander DH, Marks P, Klammer AA, Drake J et al. Nonhybrid, finished microbial genome assemblies from long-read SMRT sequencing data. Nat Methods 2013;10:563-569.

54. Seemann T. Prokka: rapid prokaryotic genome annotation. Bioinformatics 2014;30:2068-2069.

55. Bertini I, Hu X, Luchinat C. Global metabolomics characterization of bacteria: pre-analytical treatments and profiling. Metabolomics 2014;10:241-249

56. Aziz RK, Bartels D, Best AA, DeJongh M, Disz T et al. The RAST server: rapid annotations using subsystems technology. BMC Genomics 2008;9:75.

57. Kanehisa M, Sato Y, Kawashima M, Furumichi M, Tanabe M. Kegg as a reference resource for gene and protein annotation. Nucleic Acids Res 2016;44:D457-D462.

58. Felsenstein J. Confidence limits on phylogenies: an approach using the bootstrap. Evolution 1985;39:783-791.

59. Pruesse E, Peplies J, Glöckner FO. SINA: accurate high-throughput multiple sequence alignment of ribosomal RNA genes. Bioinformatics 2012;28:1823-1829.

60. Chaumeil P-A, Mussig AJ, Hugenholtz P, Parks DH. GTDB-Tk: a toolkit to classify genomes with the genome taxonomy database. Bioinformatics 2019:36:1925-1927. 
61. Meier-Kolthoff JP, Auch AF, Klenk HP, Göker M. Genome sequencebased species delimitation with confidence intervals and improved distance functions. BMC Bioinformatics 2013;14:60.

62. Richter M, Rosselló-Móra R, Oliver Glöckner F, Peplies J. JSpeciesWS: a web server for prokaryotic species circumscription based on pairwise genome comparison. Bioinformatics 2016;32:929-931.

63. Qin Q-L, Xie B-B, Zhang X-Y, Chen X-L, Zhou B-C et al. A proposed genus boundary for the prokaryotes based on genomic insights. $J$ Bacteriol 2014;196:2210-2215.

64. Konstantinidis KT, Rosselló-Móra R, Amann R. Uncultivated microbes in need of their own taxonomy. Isme J 2017;11:2399-2406.

65. Anthamatten $D$, Hennecke $H$. The regulatory status of the fix L- and fixJ-like genes in Bradyrhizobium japonicum may be different from that in Rhizobium meliloti. Mol Gen Genet 1991;225:38-48.

66. Kathiresan K, Bingham BLL. Biology of mangroves and mangrove ecosystems. Advances in Marine Biology; 2001. pp. 81-251.

67. Mokhtari M, Ghaffar MA, Usup G, Cob ZC. Variation of sediment properties among the radial profiles of fiddler crab burrows in mangrove ecosystem. Int J Zool Res 2016;12:1-10.

68. Anton A, Almahasheer H, Delgado A, Garcias-Bonet N, Carrillode-Albornoz P. Stunted mangrove trees in the oligotrophic central Red Sea relate to nitrogen limitation. Front Mar Sci 2020;7:597.

69. Kozlowski LP. Proteome-pl: proteome isoelectric point database. Nucleic Acids Res 2017;45:D1112-D1116.

70. Pawlowski K, Klosse U, de Bruijn FJ. Characterization of a novel Azorhizobium caulinodans ORS571 two-component regulatory system, NtrY/NtrX, involved in nitrogen fixation and metabolism. Mol Gen Genet 1991;231:124-138.

71. Lemmer KC, Alberge F, Myers KS, Dohnalkova AC, Schaub RE et al. The NtrYX two-component system regulates the bacterial cell envelope. mBio 2020;11:e00957-20

72. Santos-Beneit $\mathrm{F}$. The PHO regulon: a huge regulatory network in bacteria. Front Microbiol 2015;6:402

73. Wheatley RM, Poole PS. Mechanisms of bacterial attachment to roots. FEMS Microbiol Rev 2018:42:448-461.

74. Soldan R, Mapelli F, Crotti E, Schnell S, Daffonchio D et al. Bacterial endophytes of mangrove propagules elicit early establishment of the natural host and promote growth of cereal crops under salt stress. Microbiol Res 2019;223-225:33-43.

75. Soussi A, Ferjani R, Marasco R, Guesmi A, Cherif H. Plantassociated microbiomes in arid lands: diversity, ecology and biotechnological potential. Plant Soil 2016;405:357-370.

76. Marasco R, Mapelli F, Rolli E, Mosqueira MJ, Fusi M et al. Salicornia strobilacea (synonym of Halocnemum strobilaceum) grown under different tidal regimes selects rhizosphere bacteria capable of promoting plant growth. Front Microbiol 2016;7:1286.

77. Vigani G, Rolli E, Marasco R, Dell'Orto M, Michoud G et al. Root bacterial endophytes confer drought resistance and enhance expression and activity of a vacuolar $\mathrm{H}^{+}$-pumping pyrophosphatase in pepper plants. Environ Microbiol 2018;00

78. Rolli E, Marasco R, Saderi S, Corretto E, Mapelli F. Root-associated bacteria promote grapevine growth: from the laboratory to the field. Plant Soil 2017:410:369-382.

79. Zafar-ul-Hye M, Farooq HM, Zahir ZA, Hussain M, Hussain A. Application of ACC-deaminase containing rhizobacteria with fertilizer improves maize production under drought and salinity stress. Int $J$ Agric Biol 2014;16:591-596.

80. Mapelli F, Marasco R, Rizzi A, Baldi F, Ventura S et al. Bacterial communities involved in soil formation and plant establishment triggered by pyrite bioweathering on Arctic moraines. Microb Ecol 2011:61:438-447

81. Saha M, Sarkar S, Sarkar B, Sharma BK, Bhattacharjee S et al. Microbial siderophores and their potential applications: a review. Environ Sci Pollut Res Int 2016;23:3984-3999.

82. Boukhalfa $H$, Crumbliss AL. Chemical aspects of siderophore mediated iron transport. Biometals 2002;15:325-339.

83. Aladame N. Bergey's manual of systematic bacteriology. Ann l'Institut Pasteur / Microbiol 1987;138:146.

84. Bric JM, Bostock RM, Silverstone SE. Rapid in situ assay for indoleacetic acid production by bacteria immobilized on a nitrocellulose membrane. Appl Environ Microbiol 1991;57:535-538.

85. Liu Y-L, Meng D, Li R-R, Gu P-F, Fan X-Y et al. Rhodoligotrophos defluvii sp. nov., isolated from activated sludge. Int J Syst Evol Microbiol 2019;69:3830-3836.

86. Tindall BJ, Sikorski J, Smibert RA, Krieg NR. Phenotypic Characterization and the Principles of Comparative Systematics. Methods for General and Molecular Microbiology. Washington, DC, USA: ASM Press; 2014. pp. 330-393.

87. Tindall BJ. A comparative study of the lipid composition of Halobacterium saccharovorum from various sources. Syst Appl Microbiol 1990;13:128-130.

88. Kuykendall LD, Roy MA, O'Neill JJ, Devine TE. Fatty acids, antibiotic resistance, and deoxyribonucleic acid homology groups of Bradyrhizobium japonicum. Int J Syst Bacteriol 1988;38:358-361.

89. Fukuda W, Yamada K, Miyoshi Y, Okuno H, Atomi H et al. Rhodoligotrophos appendicifer gen. nov., sp. nov., an appendaged bacterium isolated from a freshwater Antarctic lake. Int J Syst Evol Microbiol 2012;62:1945-1950.

90. Pradel N, Fardeau ML, Tindall BJ, Spring S. Anaerohalosphaera lusitana gen. nov., sp. nov., and Limihaloglobus sulfuriphilus gen. nov., sp. nov., isolated from solar saltern sediments, and proposal of Anaerohalosphaeraceae fam. nov. within the order Sedimentisphaerales. Int J Syst Evol Microbiol 2020;70:1321-1330.

91. Deng SK, Chen GQ, Chen Q, Cai S, Yao L et al. Rhodoligotrophos jinshengii sp. nov., isolated from activated sludge. Int J Syst Evol Microbiol 2014;64:3325-3330.

\section{Five reasons to publish your next article with a Microbiology Society journal}

1. The Microbiology Society is a not-for-profit organization.

2. We offer fast and rigorous peer review - average time to first decision is 4-6 weeks.

3. Our journals have a global readership with subscriptions held in research institutions around the world.

4. $80 \%$ of our authors rate our submission process as 'excellent' or 'very good'.

5. Your article will be published on an interactive journal platform with advanced metrics.

Find out more and submit your article at microbiologyresearch.org. 